\title{
A Case Report
}

\section{Pulmonary Alveolar Microlithiasis \\ A rare Lung disease diagnosed by Thoracoscopic Lung Biopsy}

Rajbhandary G. L. *

\section{Introduction:}

Pulmonary Alveolar Microlithiasis is a very rare idiopathic disorder characterized by intra alveolar accumulation of calcium-phosphate which forms laminated Concertins. The lesions slowly progress and growing to diameter of 0.01 to $3 \mathrm{~mm}$ and can fill up large portions of airspaces. Secondary alveolar wall fibrosis develops and eventually the lungs become rock-hard. This disease was first described by Friedrich in 1856 AD.

\section{Etiology:}

Pulmonary Alveolar Microlithiasis has no particular geographic distribution and has been speculated to be due to a genetically determined metabolic disorder of acquired defects in calcium and phosphorous metabolism. A familial association is seen in $50 \%$ of patients. An autosomal recessive pattern of inheritance has been proposed.

\section{Clinically:}

Most patients are asymptomatic at presentation and discovered incidentally on chest Radiograph.

Dyspnoea, cough and chest pain are the most common symptoms and Expectoration of Microlithiasis have been reported.

Lung function is normal in the beginning and in advance disease a restrictive ventilatory defect may develop.

\section{Diagnosis:}

The diagnosis suspected by the characteristic radiographic finding of sharply defined nodules

* Dr. Gambhir Lal Rajbhandary, MBBS, MS Col., Consultant Cardio-Thoracic Surgeon Birendra Hospital, Chhauni,

E-mail: gambhirlrb@hotmail.com measuring less than $1 \mathrm{~mm}$ in diameter and diffusely distributed throughout both lungs with typical "Sound strom" appearance and Microlithiasis in sputum or Bronco Alveolar lavage (BAL) fluid.

The diagnosis is confined by histo-pathological study of lungs tissue from open lungs biopsy.

\section{Histopathology:}

Grossly the lungs appear gritty and hard. Microscopically the lung tissue shows alveolar spaces filled with calciospheriles measuring 250 to 750 Micro-meters in diameter. The concretion have lamellar appearance of typical "Onion-skin".

\section{Prognosis:}

The clinical course is usually slow and some patients show gradual respiratory failure. There is no definite Medical treatment. Oral medicine Disodium Etidronate has been used in some cases with no proven benefit. Lunge Transplantation has been successful in some cases.

\section{Case Report:}

A young 28 years old Royal Nepalese Army soldier on screening test for United nation peace keeping mission had on $x$-ray chest diffuse Radio opaque Shadow on both lungs field suspected of Miliary Pulmonary Tuberculosis. He was admitted in chest Dept. of Shree Birendra Hospital and was found negative for pulmonary Tuberculosis. He was free of symptoms and was suspected of Interstitial Lung disease.

He was referred to Cardio Thoracic Surgery department for open lung Biopsy for Histo Diagnosis of his disease. He was admitted in Cardio Thoracic surgery ward for Evaluations and open 
lung Biopsy on 10/7/2061 B.S. (2004) on 18/7/2061 he had Thoracoscopic lung Biopsy from left lung upper lobe. He had an uneventful during post operative period and discharged on 30/7/2061.

\section{Histo Pathology Report:}

Lung section showed numerous calcospherites filling the alveolar spaces and diagnosed as Pulmonary Alveolar Microlithiasis.

Discussion: Bilateral Miliary Pulmonary Opacities in chest Radiography is usually seen in patients of Miliary Pulmonary Tuberculosis and Interstitial lung disease in our clinical practice in developing countries. Incidence of Pulmonary Alveolar Microlithiasis in our country is very rare and it is wise to follow up the case for study to find out the Etiology and treatment of the disease in future.

Conclusion: When we come across patients presenting with Bilateral Miliary Pulmonary
Opacities in chest Radiography we are advisey exclude Pulmonary Alveolar Microlithiasis.

\section{References:}

1. Kanra G. Tanyol E. Goemen A. et Pulmonary alveolar Microlithiasis (AC Report). Turk J. Pediatr 1988:30:61-7

2. Mariotta S. Guidi L, Mattia P. et Pulmonary Microlitiasis Report of , Cases. Respiration 1997;64:165-9

3. Prakash UB, Barhum SS, Rosenow EC et al Pulmonary alveolar Microlthiasi review including ultra structural pulmonary funcition studies. Mayo 1 Proc, 1983;58:290-300

4. Singh NK, Gupta A. Pulmonary alve Microlithiasis J. Assoc Physicians In 1995;43:647-8

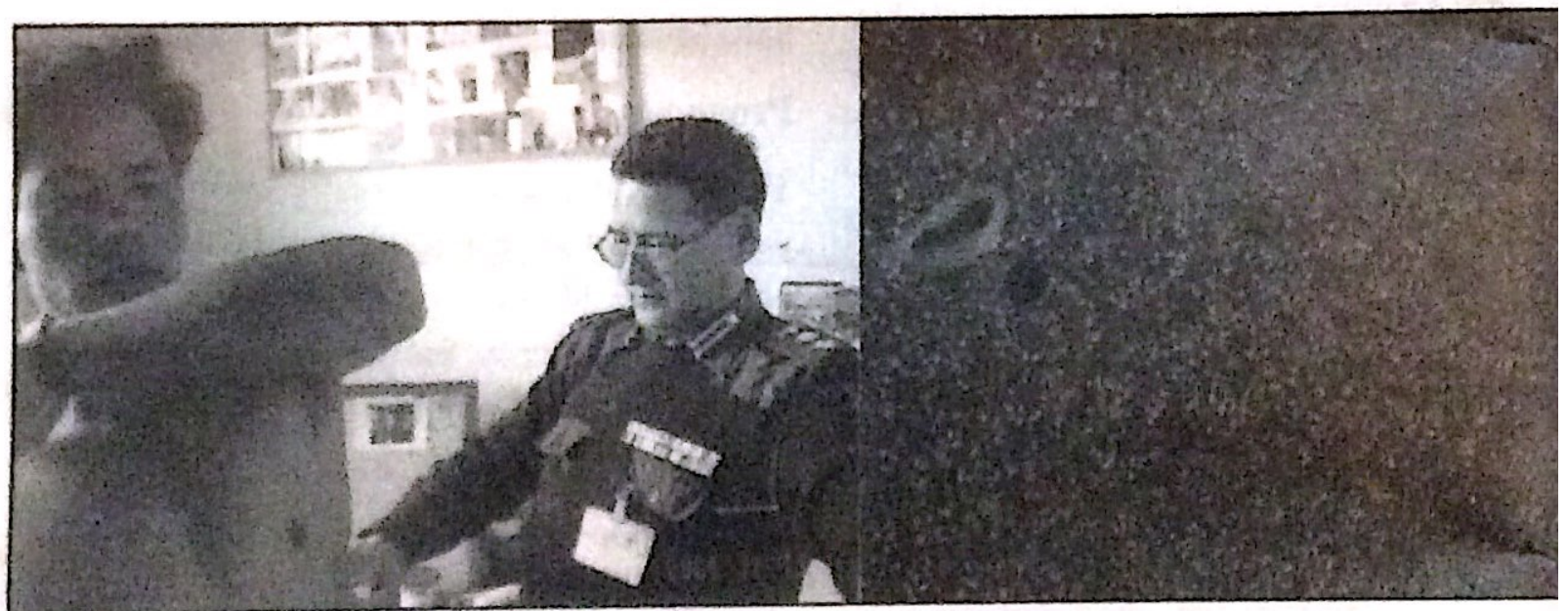

Fig No, 1: Paimonary alveolar microlithiasis

Fig No. 2: Pulmonary alveolar microlithiasis

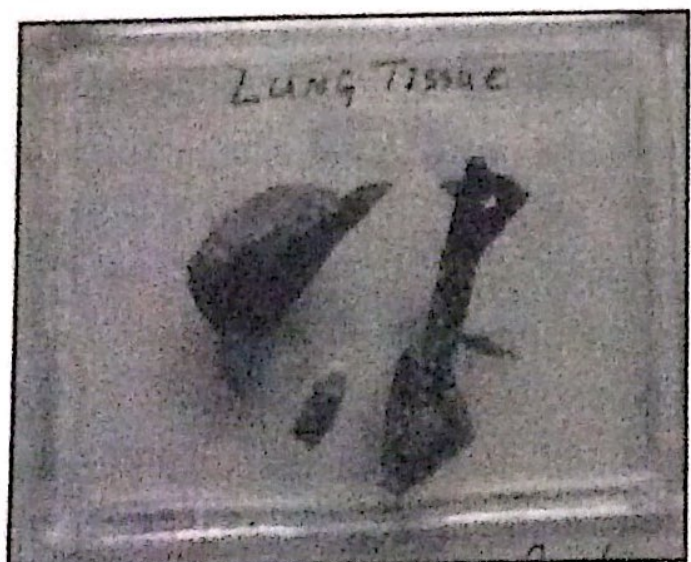

Fig No. 3: Ling tissue (Thoracoscopic Lung Biopsy

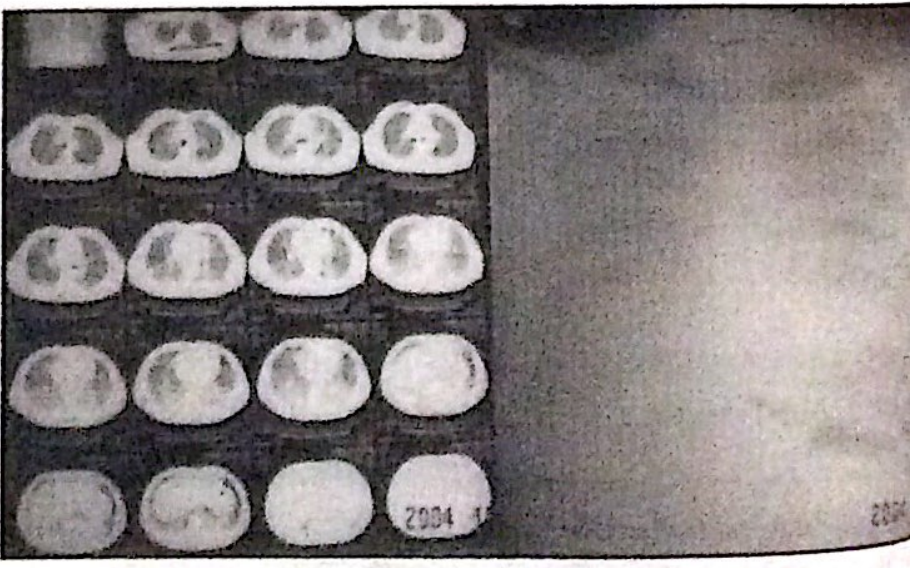

Fig No. 4: Pulmonary alveolar microlithiasis 